\title{
Role of online media in agriculture development in Vietnam
}

\author{
Thi Thuy Hang Nguyen ${ }^{1, *}$ \\ ${ }^{1}$ University of Social Sciences and Humanities, Vietnam National University, 336 Nguyen Trai \\ Street, Hanoi, Vietnam
}

\begin{abstract}
In the history of Vietnam's establishment and development, agriculture has always been an important economic sector. In 2019, the agriculture, forestry, and fishery sectors accounted for $13.96 \%$ of Vietnam's GDP. However, this is also the year that witnessed the GDP growth of the agriculture sector plummeted to only 2.2 percent. There are many factors responsible for the decline in the share of agriculture in economic growth, while other sectors have increased. In the current context, with the outstanding development of science and technology, global networking and information society, every aspect of development including agriculture development cannot be separated from the operation of media, especially online media. This paper analyses the role of online media in agriculture development in Vietnam by analyzing hundreds of articles published in different electronic newspapers. The paper particularly examines 217 news-articles produced on VnExpress, the most read Vietnamese newspaper. While discussing the advantages and disadvantages of the role of media in agriculture development, the paper also explores some new paradigm and recommends to enhance the role of online media for digitizing the development of agriculture in Vietnam in this digital age.
\end{abstract}

\section{Introduction}

Agriculture is an essential-need producing factory for society and an important industry for economic growth in many countries of the world. Therefore, agriculture development and the role of media have attracted the attention of many scholars around the globe.

Some point out the agriculture and the food industry in the information age, when individual characteristics shape information needs, and information provided through mass media and labeling [1]. The studies show that structural changes in agriculture, the invention of new types of agricultural technologies, ever sliming public budgets, efforts of decentralized governments, and emerging information and communication technologies have led to a pluralistic approach [2]. They even predict and broadcast the speed and extent of adoption of new agricultural innovations. Thus, information technologies are needed to publicize the policies, plans, and decisions for agriculture development [3].

Some social scientists examine the impacts of the use of social media in agriculture

\footnotetext{
* Corresponding author: hangkhct@vnu.edu.vn
} 
promotion $[4,5]$. They concede that the platforms of social media (Facebook, YouTube, WhatsApp, blogs, pages, and groups) are handy tools for the marketing of agricultural products because it saves time and cost of both parties - the producers and consumers, for getting information. However, some of them identify various barriers to adopting those virtual platforms for the promotion of the industry. Mainly, researches in developing countries such as India, Pakistan, and many others, found to be engaged in analyzing the role of mass media for the dissemination of information regarding new agricultural technologies among farmers $[6 ; 7 ; 8]$.

In Vietnam, some agriculture-focused researchers discuss on various emerging avenues in the agriculture development and promotion, such as land reform and the development of commercial agriculture policy and issues [9]; upland rice, household food security, and commercialization of upland agriculture [10]; the effects of seasonal migration on agricultural production in rural areas [11]; communication and agricultural development [12]; the ups and down in agriculture after 30 years of renovation [13], agriculture and income distribution in rural Vietnam under economic reforms [14], and so on.

However, it is surprising that researchers have rarely focused on the role of online media in agriculture development in Vietnam. In the contemporary world, no sphere of development can be separated from media activities. Therefore, the role of media to promote and protect agriculture development in Vietnam is very crucial.

Mass media is loosely defined as "represent[ing] the most economical way of getting the story over the new and wider market in the least time" [15]. Media generally defined "the main means of mass communication, esp. newspaper, radio and television regarded collectively; the reporters, journalists, working for organizations engaged in such communication" [15]. Mass mainly constitutes "a large number of human beings, collected closely together or viewed as forming an aggregate in which their individuality is lost" [15]. Nevertheless, the general concept of mass media, as Nickolas Luhmann elaborates, is "[the] institutions which make use of copying technologies to disseminate communication" [16]. Luhmann presents the "efficient" or "economic" aspect of mass media. In his view, Media are anything "that they generate large quantities of products whose target groups are yet undetermined" [16].

The various studies analyzing the impact of media on human actions confirm that information and knowledge are provided to receivers through channels so that people will understand and have the ability to follow the directions of information, which can create actions of individuals and groups of people. The lists of some typical mass media are books, printed newspapers, radio, television, cinema, the internet, videotapes, audiotapes, disks. Thanks to information technology (IT), multimedia has become one of the most trending mass media around the globe in the $21^{\text {st }}$ century. This paper also presents a study of news coverage relating to agriculture development in the online newspapers in Vietnam because of their significant influence and impact on contemporary Vietnamese society.

Online media most commonly refers to telecommunications and computer interactivity, as well as specific media such as online newspapers, blogs, wiki-related content, video games, and social media. However, this paper is based on the analysis of official resources of online publications and interactive reader's feedback on several news articles. Online media make sense only when it stimulates the interests of the intended audience, convinces about their perceptions, brings changes in attitudes and actions. Due to such quality of online media in Vietnam, people have noticed a widely increasing TRP (A target rating point (TRP) is a metric used in marketing and advertising to indicate the percentage of the target audience reached by campaign or advertisement through a communication medium) of online newspapers devoted to development goals.

An online newspaper stands for a web-based version of a paper, which comprises either a stand-alone publication or the online version of a printed periodical or both. In this 
webbed era, going online means creating more opportunities for print media, such as competing with on-time broadcasting journalism for presenting breaking news to the audience on-time. "The credibility and strong brand recognition of well established newspapers, and the close relationships they have with advertisers, are also seen by many in the newspaper industry as strengthening their chances of survival" [17].

As the Government's report reveals, "Vietnam has 850 print and online newspaper agencies by November 2019. Regarding radio and television, there are currently 72 agencies that have secured the license to operate with 2 national stations, 64 local stations, 5 television channels, with a total of 87 radio and 193 television channels. Currently, over 41,000 people are working at media industries (all 4 types), of which 20,407 journalists have been granted press cards" [18].

The Agenda Setting Theory was invented by Maxwell McCombs and D. Shaw in the United States of America, theorize the possibility of the media's influence on the public [19]. In 1968, when the media made headlines about the presidential election in the USA, two media experts conducted in-depth research on the voters of that election. They found that the close relationship between perceptions and judgments of voters on the key issues of American society is influenced by issues continuously published on the media. For the Agenda Setting theory, two underlying assumptions which underpin most researches are: (1) the media does not reflect the reality, they filter and reframe it; (2) then a piece of news is mentioned regularly and continuously by the media, the public remember it and consider it more important than other information. "The basic thesis of this theory is that the mass media has a function to set up the "agenda" for the public. The news and communication activities of news agencies influence the judgment of public audiences to the "big stories" of the surrounding world and their importance by enriching the "programs" with different highlights, thereby influencing and creating future guidance" [20]. From this, a question arises that do the mass media really publishing for the development and promotion of agriculture in Vietnam? Do they guide the public about the importance of agriculture development in Vietnam? What kind of role mass media is playing in agriculture development in Vietnam? The paper discusses these questions in subsequent sections.

Currently, there are about $65 \%$ of Vietnam's population living in rural areas. Therefore, the need for comprehensive rural-agriculture development, in the standard of modernization, has become a priority and a key part of the national development strategy. To achieve the priority, the Communist Party of Vietnam (CPV) has many passed resolutions for the development of agriculture, farmers, and rural areas. Resolution of the 7th Central Congress, Session X on Agriculture, farmers, rural areas; Resolution No. 32/2016/QH14 dated November 23, 2016, of the National Assembly, has emphasized on continuing for improving the effectiveness and efficiency of the implementation of the national target program on new rural construction; The core-spirit of resolutions states "all people should unite to build new rural areas and civilized cities," according to Directive No. 10-CT/TW, dated December 15, 2016, of the Party Central Committee's Secretariat, are vivid examples and have been put into practice.

After 30 years of renovation period, Vietnam's agriculture has achieved significant progress. From an impoverished country until the late $80 \mathrm{~s}$, Vietnam has become one of the leading rice exporters in the world now, which generates billions of dollars in export turnover. In Vietnam, the model of development is defined as the effective implementation of socio-economic goals. The issues of development are the forefront of Social goals, and social goals are the development of society. There is a trendy slogan sticking on each Vietnamese tongue is "we choose the mode of development in which the economy and society will merge." It further elaborates as "development is different from growth. Growth is about quantity, and development is quality. Growth is partial economic progress. Development is overall progress in terms of economy, politics, society, culture, and 
environment" [21, p. 391]. In this way, development has become a culture in Vietnamese society. The goal of agriculture development in Vietnam is understood from such a comprehensive perspective. Therefore, mass media can play an ultimate role in national development by disseminating that message of development to the public.

\section{Materials and methods}

Data collected from the enforcement and specialized agencies in Vietnam is probably the most reliable source to assess the actual magnitude of agriculture development, and it is also the firm base of this paper.

This paper uses the content analysis method: Analyze the content of articles on agriculture on online newspapers in Vietnam for one year, from March 2019 to March 2020. The primary focus of the paper is to access, discuss, analyze 217 agriculture-related articles published on VnExpress in the stipulated timeframe. VnExpress is the most read Vietnamese newspaper in Vietnam as well as international.

The paper also discusses the literature review as a methodology, and it is based on published data of the General Statistics Office of Vietnam and articles on official newspapers, which shows the statistics on agriculture, forestry, and fishery as well as the economic structure of every year.

The paper adopts historical, descriptive, and analytical research methods and analyzes both primary and secondary data to prove the central thesis of research.

\section{Results}

After 30 years of Doi moi (Renovation), Vietnam's agriculture has made many significant achievements. "The annual growth rate of the Gross Domestic Product (GDP) of the agroforestry and fisheries sector is 3.7\%. The manufacturing structure has had initial steps towards modernization, with the proportion of agricultural labor reduced from $70 \%$ in the 1990 s to $47 \%$ in 2019 " [14, p. 15].

From 2011 to 2019, Vietnam's agriculture has developed quite comprehensively in various fields, and it is moving towards increasing profitable products and gradually modernizing goods.

In the period 2011-2015, the average GDP growth rate of agriculture reached $3.13 \%$ per year, exceeding the target set by the Resolution of the 11th Party Congress (2.6-3\%). In 2017 , the agricultural sector achieved an increase of $2.9 \%$, significantly higher than that of $1.36 \%$ in 2016 . In 2018, the agricultural sector achieved an increase of $2.89 \%$. In 2019 , the agriculture, forestry, and fishery increased by $2.01 \%$, contributing $4.6 \%$ to the overall growth of the economy. Therefore, Vietnam's GDP in 2019 has achieved impressive results with an increase of $7.02 \%$ (exceeding the target set by the National Assembly from 6.6$6.8 \%$ ). The trends of target-achievements confirm the timeliness and effectiveness of the solutions issued by the Government, drastically directing all levels, sectors, localities, and the business community to implement and exceed the growth targets. Although the growth rate in 2019 was lower than the same at $7.08 \%$ in 2018 , which is the highest than that of the years 2011-2017. The agriculture, forestry and fishery sectors achieved low bonuses in 2019. The occurrence of severe drought, the impacts of climate change on crops production, and the outbreak of African swine fever (ASF) in the livestock industry severely damaged the economy of Vietnam in 2019 (African swine fever was first detected in Vietnam in February 2019 and has spread to all 63 provinces in Vietnam. ASF in Vietnam has led to the death and culling of about 5.9 million pigs or about 22 percent of the total swine population). Agricultural products also experienced massive difficulties in 
consumption markets and export prices in that year.

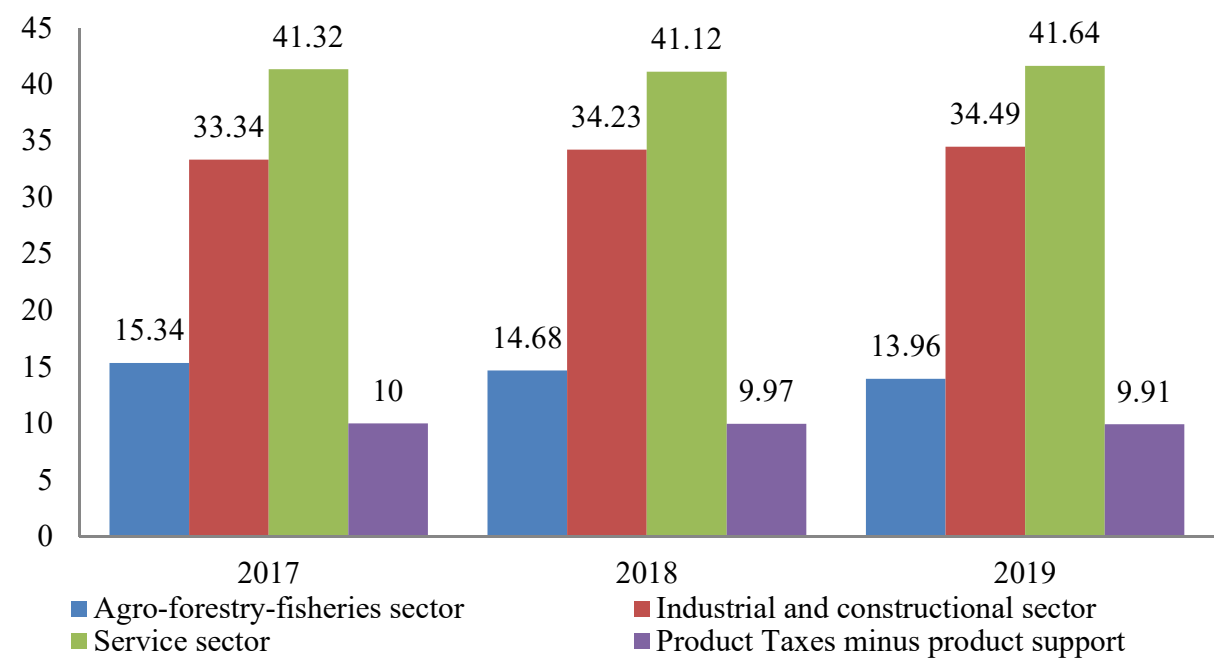

Fig. 1. Economic sectors of Vietnam (2017-2019).

The figure above shows that agriculture has always been an important economic sector in Vietnam. The share of agriculture in GDP decreased from $20.1 \%$ in 2011 to $19.7 \%$ in $2013,17.4 \%$ in $2015,15.34 \%$ in $2017,14.68 \%$ in 2018 , and $13.96 \%$ in 2019 . Although in recent years the proportion of the agricultural economy has decreased in the country's economic map, the rapid progress and modernization in the industrialization sector are supposed to be reasonable hope for future economic growth. Achieving target economic growth depends on the level of synergetic efforts applied by all stakeholders. The dissemination of real information regarding target achieved and to be achieved makes people aware and motivated to achieve the goal. Media, especially online media, is the most effective way to disseminate information to the citizens. Therefore, this study focuses on the role of online media in agriculture development in Vietnam. The consecutive sections discuss the role being played by Vietnamese online newspaper, esp. vnExpress, in the field of agriculture development in Vietnam.

\subsection{Introducing the achievements of Vietnamese agriculture}

Over the past few years, Vietnam's agriculture has made remarkable progress. However, the people were not quite aware of that progress and achievements until it was published and disseminated to them by the online news media, esp, online newspapers. Thus, online news media has been playing a very crucial role in making people aware of agriculture development in the country.

First, the National Target Program on New Rural Construction (New Rural Construction Program) has achieved comprehensively.

Online media reported on the National Conference, summarizing ten years of new rural construction on the morning of October 19, 2019.

"After nine years of implementing the National Target Program on New Rural Construction, the whole country had 4,665 communes (52.4\%) recognized to meet the new rural standards; eight provinces and cities have 100\% of the communes recognized to meet the new rural standards... The Prime Minister has recognized 109 district units of 41 provinces and cities under the Central Government as meeting the new rural standards; the program was completed almost two years earlier than the target assigned by the Party and 
National Assembly". "Prime Minister Nguyen Xuan Phuc affirmed that the National Target Program on New Rural Construction (in the period 2010 - 2020) has created a historical breakthrough and changed the face of rural areas. Vietnam; farmers' position was improved, their lives improved clearly; Agricultural production continued to be restructured towards a more modern and sustainable manner. ... The program has mobilized a large amount of resources with VND 2.4 million billion, equivalent to raised more than USD 10 billion annually for the development of infrastructure, production, life, culture, and society" (PV, Nhan Dan, 20/10/2019).

It is said that the new rural construction program is one of the essential achievements for the development of agriculture, rural areas, and Vietnamese farmers over the past decade.

Second, agriculture has a steady growth in scale, productivity, and quality.

The media publicized the essential achievements of agriculture development in recent years are strong growth, productivity, and quality.

"A number of agricultural products from small-scale production have developed into key export products such as coffee, rubber, pepper, and cashew. In 2018, Vietnam exported more than 7 million tons of rice. In particular, the fishery industry, still very poor in 1995, has had good growth. The area of aquaculture increased from nearly 200 hectares in 1995 to nearly 1 million hectares in 2017. Besides, in the integration process, agriculture is a sector with a trade surplus that is always positive, averaging growth rates $14-15 \%$ per year. The import-export turnover of agriculture, forestry, and fishery has increased sharply, in which export turnover increased from less than 5 billion USD in 2000 to over 40 billion USD in 2018. Up to now, the proportion of some Vietnamese agricultural products accounts for nearly $50 \%$ of the world. In which cashew nuts, black pepper ranked No. 1 globally in terms of quantity and value; coffee beans and sliced cassava ranked No. 2 globally in terms of quantity and value" (Bich Nguyen, Bien Phong Newspaper, 9/11/2019).

"In the context of market difficulties, prices of most agricultural commodities decreased by $10 \%-15 \%$, but the total export turnover of agriculture, forestry, and fishery in 2019 were estimated at 41.3 billion USD, an increase of about $3.2 \%$ compared to 2018 , particularly the forestry sector reached over 11.2 billion USD, increased up 19.2\%. The trade surplus of the whole industry was estimated at a record of 10.4 billion USD, which increased by 19.3\% compared to 2018. Vietnam's agriculture and rural development sector continued to maintain eight commodity groups with export turnover over 1 billion USD; in which four items of over USD, three billion are wood and wood-products, shrimp, vegetables, and cashew" (Nguyen Xuan Cuong, Communist Review, 16/3/2020).

Third, the organization of agricultural production has been renewed, cooperatives and agribusiness have flourished, becoming a driving force for agricultural and rural development and restructuring of the agricultural sector.

"In 2019, 6 new agricultural cooperative unions and 1,800 agricultural cooperatives were established, bringing the total to 45 agricultural cooperative unions and 15,300 agricultural cooperatives. In which, nearly $73 \%$ of cooperatives operated effectively (in 2018 it was 55\%). The percentage of cooperatives participating in agricultural product consumption services for cooperative members increased by less than 10\%; previously, it was $24.5 \%$.

The country has total 36,000 registered agriculture farms under the new criteria, an increase of 500 farms compared to 2018; farms increasingly use more land, labor, and produce large quantities of agricultural commodities; organization of chain production, large-scale cooperation continues to be replicated in many fields and many localities" (Khanh Linh, Vietnam Financial Times, 21/12/2019).

From the above analysis of the Government's policies for agriculture development, it 
reveals that the Ministry of Agriculture and Rural Development has created a favorable and supportive environment for agricultural cooperatives and businesses, forming links between producers, enterprises, cooperatives, and consumers. The news over online media reveals that the force of agricultural enterprises continued to grow strongly. In 2019, there were 2,756 newly established agriculture-based businesses enterprises all over the country, which was an increase of $25.3 \%$ compared to 2018. The total number of enterprises investing in the development of agriculture in this country is 12,581 , which is increased by up to $36.2 \%$. In addition to the investment and development of small and medium-sized businesses, several large corporations and businesses have expanded their investments in agriculture, especially high-tech agriculture, such as TH, Vinamilk and Dong Giao, Nafoods, Dabaco, Masan, Lavifood, Ba Huan, Bien Dong, and so on. Notably, many online newspapers usually publish news about high-quality agricultural models in the country. The online media widely covers and publish news regarding the programs and policies for building clean and green agriculture-based industries, growing organic agricultural products, and encouraging the application of new technology for the agriculture development in the future.

\subsection{The problems, limitations, and challenges in Vietnamese agriculture}

In addition to praising the agricultural sector's efforts and achievements, the online media pointed out the limitations and challenges of Vietnam's agriculture.

Firstly, agriculture development and rural economy are unstable and vulnerable to natural disasters, epidemics as well as unpredictable fluctuations in the market. Resilience is limited, especially to new diseases. In 2019, the effort of the Government to prevent and control the African Swine Fever (ASF) epidemic proved embarrassing and ineffective despite the extreme attention of the Prime Minister. Although the disease gets controlled so far, the livestock industries had to pay a severe price for that. There was severe damage that more than 342 thousand tons of pork were destroyed. The destruction of such a large amount caused an imbalance between the supply and demand chain. That imbalance created a massive price-hike in the consumer price index in the last month of the year, which affects social security considerably. The state budget had to allocate more than VND 5,000 billion in prevention and control of the ASF.

Series of articles on online media had mentioned that natural disasters impacted Vietnam's agriculture very severely. Such as, "Mekong Delta hit by worst drought ever" (Huu Khoa, VnExpress, 21/3/2020), "Neither insurance nor assurance: Vietnamese agriculture left in the lurch": "Storms, floods, other disasters are not uncommon, but Vietnamese farmers can only lament: "Perhaps it is just God plan" (Lam Trong Nghia, VnExpress, 15/8 /2019), and so on.

Another limitation of agriculture development is the problem of product consumption. At present, Vietnam's agricultural market is highly dependent on China. Whenever there are difficulties in exporting products to the Chinese market, immediately, the products were stagnant, and the farmers get in the loss. There were many movements of "rescuing" for farmers in the last years, such as rescuing watermelons, rescuing dragon fruits, rescuing sweet potatoes. Many articles on VnExpress, in particular, and on online media, in general, frequently published this issues on different titles, such as "Agriculture export to China could take $\$ 800$ million hits" (Anh Minh, VnExpress, 8/2/2020), “Agriculture exports to China slacken as conditions tighten" (Thi Ha, VnExpress, 9/6/2019), “Agriculture exporters suffer as China rules tighten" (Thi Ha, VnExpress, 1/7/2019), and so on.

Secondly, agricultural-based farms and industries unevenly deployed and developed in rural areas do not meet the requirements of rules and regulations.

While production linkage, according to the value chain, has not become so popular and 
mainstream, the deep processing industry has not developed as per the requirement yet. Furthermore, the use of unskilled labor in agriculture industries makes productivity low, and that makes the chance of being post-harvest losses are high.

Message from a scientist disseminated on web-based newspaper state, "low efficiency is the cause of the situation of leaving the field barren, nobody renting the land, is becoming more and more popular. If labor is poured in, on average, a hectare of agricultural land in Vietnam can earn about 82 million VND each year. With an average of " 2 sào Bắc Bộ" ("2 sào Bắc Bộ" = $720 \mathrm{m2}$ ), the harvest is not worth much" (Nguyen Lan Dung, VnExpress, 27/8/2019).

Thirdly, the growth curve of export turnover seems running down due to the decline in export prices of major agricultural products. The progress of the EC "Gold Card" for fishing is still slow, erosion of riverbanks is going on, the reoccurrence of drought and forest fires continue, and resources for the agriculture sectors are limited. Although the mechanisms to attract investment in agriculture have been improved, they could not have created a favorable environment and attracted business-man to invest in high-tech agricultural production yet. Also, the capital investment for agriculture development has not been renovated and created favorable conditions for businesses, cooperatives, and farmers. The capital is still inaccessible for them. Such problems of investment and inaccessment are widely covered on online newspapers and firmly advocate for the need for changes in government's policies, investment plans of businesspeople, and farming style for farmers themselves.

\subsection{Proposing some solutions for Vietnam's agriculture development}

Not only performing the traditional function of only disseminating information, but the mass media also performing the function of social supervision and criticizing for the lack of attention on agriculture development in Vietnam. Besides pointing out achievements and challenges in agriculture development, the online newspapers also proposes some solutions for agricultural development in Vietnam. They are:

Firstly, focus on developing specific agricultural products, regional specialties, developing value chains of product groups.

The diversity of climate, land, geographical position in Vietnam allows every locality and region to yield a variety of agricultural products. These types of agricultural products and specialties of Vietnam are not only loved by the people inside the country but are also well received by many countries around the world. Currently, Vietnam's agricultural products are available in 185 countries around the globe (PV, VnExpress, 2/5/2019). The program of producing "one commune one product" (OCOP) has been strongly implemented throughout the country, which has proved to be a driving force for the development of products of many other special regions, which is creating resilience for both agriculture and rural areas. Specific agricultural products of each locality support to develop the value chain in product specialty.

"The methods of selection for developing value-chains of product groups are based on the following principles: Taking enterprises as the nucleus, associating with members in the value chain. Besides the leading role of large enterprises, especially the State pays attention to the development of small and medium enterprises, start-ups, and farmer organizations, taking these as an important foundation and intermediary to connect smallholder farmers to agricultural value chains comprehensively and sustainably" (PV, VnExpress, 2/5/2019). Farmers' awareness of the linkage chains to be raised, as "currently $11-14 \%$ of agricultural output through linkage is too small, which implies a huge potential for tens of millions of hectares of agriculture, and in the coming time, Vietnam needs to strengthen further the integration process in agriculture" (PV, VnExpress, 2/5/2019). 
To achieve the goal of agriculture development in Vietnam, agricultural production in the rural area needs to be expanded on a massive scale; the high priority should be given for the development of regions with specific products to meet the demands of the domestic market as well the demand of exporting abroad. Each locality must have a strategy to develop agricultural products according to the specialties of their soil. Moreover, it would be crucial to do special planning for a particular product in particular areas; and trade promotion and business cooperation so that typical products shall get the unique brand name in the domestic as well as in the world market. In order to do that, it is necessary to invest in for the promotion of products, bringing products to exhibitions, advertising and developing as tourist areas and sightseeing, and promoting as a local product. The State should support capital investment, grant rights for using land for each type of agricultural product, support to develop exporting strengths, focus on developing agricultural and communication-related infrastructure. Many large-scale production areas should be established to meet the processing and export demands in the market. Particularly, the state must have a strong mechanism to monitor and control the haphazard development for agricultural promotion and protection.

Secondly, the application of scientific and technological advances to agricultural production

The application of scientific and technological advances in the field of agricultural development is essential in the contemporary modern world. The state should have a clear policy to establish a link among agricultural scientists, entrepreneurs, and farmers to promote the application of scientific innovations to yield high agricultural production. The State should invest in scientists so that they could find better ways to increase productivity, improve quality and efficiency in agricultural industries. The State should also increase capital investment for agricultural extension programs, transferring scientific and technical advances, and encourage to create cohesion between farmers and enterprises, which can ensure better output. On the other hand, each special production area should have a training strategy to improve qualifications for allocating appropriate staff for extension workers in the respective locality. Especially, the network of extension-workers in communes should make skilled for improving the quality and efficiency of the process of transferring and applying science and technology in agricultural production.

Many news-articles published on online newspapers suppose to propose models of hitech agricultural production by applying science and technology in agriculture development. "In order to have dream agriculture, we must promote the creation of new technologies and techniques and enhance the transfer. During the period 2013-2016, our country scientists have created up to 149 plant varieties and animal breeds that are qualified for production, and the agricultural industry has also recognized 65 technological processes and 35 advanced technologies" (Nguyen Lan Dung, VnExpress, 27/8/2019). Alternatively, it requires "technology application for product traceability," "smart agriculture development, reorganizing production and forming chain links," "digitalization for all businesses, from raw materials, production, to sales (services)" (PV, VnExpress, 2/5/2019).

Besides, it is necessary to promote safe agricultural production, improve production efficiency, protect the health and rights of consumers, and meet the requirements of international standards. Many news-articles quote the foreign experts'remarks that "Vietnam needs to meet the environmental sustainability in agriculture development," (PV, VnExpress, 2/5/2019) and somehow they are very true in this context. Therefore, the researcher also suggests that the states should introduce new technologies in all fields of agriculture development. They are production, harvest, storage, processing, transport, and consumption of products. The pilot construction of several hi-tech parks based on biotechnology, information technology is also needed to promote agriculture development. 
Thirdly, forming strong agricultural corporations

The formation of strong agricultural corporations is essential in the context of the globalized market and economy. Establishing strong agricultural corporations shall help to improve the quality of Vietnamese agricultural products, and maintain stability, and further helps to develop the domestic market. Especially in recent times, many types of agricultural products of other countries have entered in Vietnam market and compete very strongly with local products. Therefore, the State should have policies to encourage businesses to invest in agriculture as proposed in Decree No. 210/2013/ ND-CP dated December 19, 2013, encouraging businesses to invest in agriculture and rural areas. According to the newly issued Resolution 53, the Government aims that by 2030, Vietnam's agriculture will be in the list of 15 countries of the most developed agriculture in the world, and the processing of agricultural products will be in the list of 10. Furthermore, it is supposed that there will be 80,000-100,000 enterprises investing in agriculture, of which about 3,000-4,000 large-scale enterprises, by 2030 (Phuong Dong, VnExpress, 20/7/2019).

There have been some businesses investing in agriculture, such as Vingroup Group, which has officially announced its entry into the agricultural sector with the VinEco brand. VinEco's goal is to provide clean and safe food products, moving towards bringing some of Vietnam's strong agricultural products to the world. "VinEco Company has chartered capital of VND 2,000 billion, deploying agricultural activities in many localities throughout the country, in which initially focusing on the field of cultivation, applying advanced technologies and leading techniques in the world to provide organic vegetables and fresh vegetables to the market according to VietGAP and GlobalGAP standards" (Minh Phuc, Vietnamese Agriculture, 23/3/2015). In addition to VinEco, there are many other large enterprises such as Vinamilk, Nafoods, TH, Dabaco Vietnam, Masan, Lavifood, are opting to invest in agriculture development in Vietnam. However, the growth of businesses in this sector is modest compared to the available potential. Specifically, the number of businesses investing in agriculture accounts for only $8 \%$ of the total strength of businesses across the country.

The current form of agriculture-based organization is still in the form of households with over 9.2 million households (Phuong Dong, VnExpress, 20/7/2019). Therefore, Vietnam needs a leading enterprise to lead the chain of agricultural production. It could be a business holding output, or holding an intermediary product, as long as it ensures the condition of financial resources, strong enough to create a strong influence, professional and branded activities. "The State should also set up ethical standards for both businesses and businessmen, for example, they must be dedicated to serving the country" (PV, VnExpress, 2/5/2019).

Fourthly, continue to improve the laws and policies and effect of state management on agriculture

Many articles published on online media suggest that the State should continue to improve the laws to maintain the quality of agricultural products, ensure food safety in harmony with international standards. Further, it should create favorable conditions for people and enterprises to invest in agriculture and develop high-quality agricultural value chains. The State should proactively handle issues of food (in)security. The issues are timely checking and verifying to provide accurate information to consumers, avoiding misunderstandings and confusion among people, continue to solve technical barriers on food hygiene and safety in order to expand the export of agricultural, forestry, and aquatic products to other countries. At the same time, policies should be in place to help farmers avoid risks, such as agricultural insurance. "There is no Government or other entity that can accurately predict all the risks and eventualities in agriculture, so policies to keep farmers safe from them are not there. That is why the Governments must develop some "shockproof mattresses" for farmers to take the secure fall when unforeseen circumstances hit them. 
Agricultural insurance is a key solution to the problem" (Lam Trong Nghia, VnExpress, 15/8/2019).

More important is that the State should focus on exploring market development. Besides, developing only the domestic market, it is necessary to develop a comprehensive plan to take advantage of free trade agreements (FTAs), especially the Comprehensive and Progressive Agreement for Trans-Pacific Partnership (CPTPP); Vietnam - EU Free Trade Agreement (EVFTA) to promote the export of key agricultural products; maintain and sustainably develop the Chinese market; expanding the agricultural market to new structured economies such as Japan, Korea, India, EC, Middle East.

\section{Discussion}

Focusing on the online newspaper, VnExpress, the most read Vietnamese newspaper, the paper extensively examined the agriculture-related news and articles published within one year, from March 2019 to March 2020. The figure below shows the detail categories of news as follows.

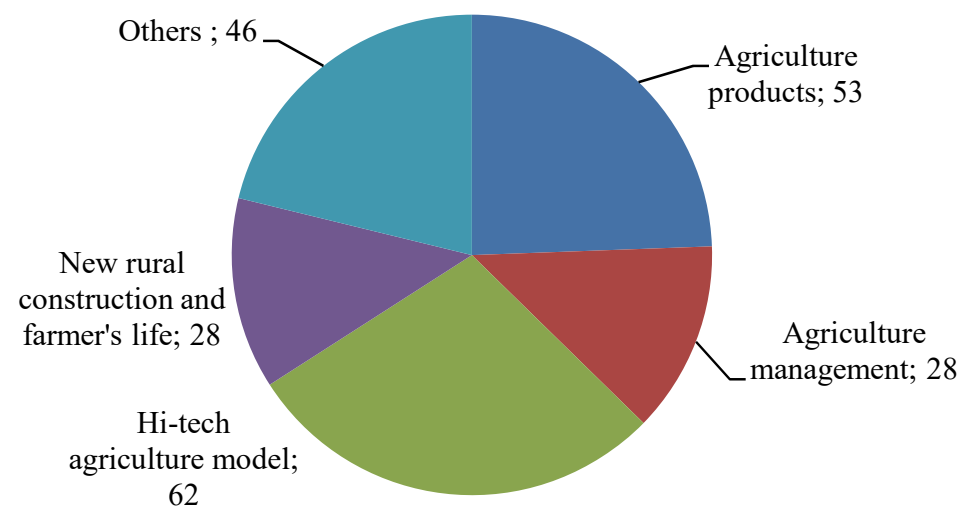

Fig. 2. The contents of agricultural articles on VnExpress, since March 2019 to March 2020.

The researcher found that the VnExpress had published around 217 news-articles on several titles regarding agriculture development, promotion, and protection in the stipulated time frame, March 2019 to March 2020. The articles were analyzed based on all prospects of agriculture development in Vietnam. The main basis of analysis covers both the achievements of Vietnamese agriculture as well as the difficulties, challenges and proposed solutions for agriculture development. Firstly, articles were divided into five broad categories based on the nature of the contents of the articles (see figure, above). In particular, the content of the high-tech agriculture model, including agricultural corporations that have applied science and technology in agricultural production and the model of organic agriculture and clean agriculture, is written the most, with 62 articles. It is also the general trend of articles on agriculture in the mass media in Vietnam nowadays. Thereby, it shows the inevitable need for restructuring of agriculture in the direction of building hi-tech technology-based agriculture industry, organic agriculture, and sustainable development.

The following content covered were articles on agricultural products, including crop, livestock, and processed products. Vietnam is a country with rich and diverse agricultural 
products, many regional specialties. It is found that VnExpress had covered this category very broadly. Total 53 articles found in this category introducing specialties in unique localities such as Ha Giang oranges, Chau Duc avocado, Bac Kan mandarin, Doan Hung grapefruit, Tra Vi dragon fruit, Dong Du guava, Sa Pa sturgeon, Dong Thap dried fish, Ca Mau squid, and so on. Articles introduce local specialties to readers in order to expand the domestic and foreign consumption markets for the products. At the same time, it is recommended that localities should focus on developing unique or different commodities like fruit trees and key breeding areas in order to bring high incomes to farmers.

Surprisingly, the number of articles regarding the State's approach for agricultural management; and the new rural construction and farmer's life are equal in numbers, i.e., 28 articles. Although these are all very significant issues in Vietnam's agriculture development, the number of articles on these issues in one year is quite small compared to others. In the category of State management of agriculture, the articles mainly raised issues regarding agricultural tax exemption, ODA support for agriculture, rice export policy, the export of agricultural products, and food safety control measures, and so so. In the next category, new rural construction in Vietnam and farmer's life, the articles mainly talk about the difficulties in the lives of farmers, the issue of "rescuing" annual agricultural products, and new rural construction in Vietnam. VnExpress, as well as the online newspapers in Vietnam, in general, have not spent enough space to analyze the agricultural management issues and the lives of farmers in rural Vietnam.

The "Others" category generally comprises issues regarding food processing techniques, farming practices, animal husbandry, and so so. The number of 46 articles on were related to daily life, which shows the preference of, VnExpress newspaper. Her focus is aimed at general readers, showing the essential needs of life, rather than discussing the macro issues of the country. That is also the general trend of online newspapers in Vietnam in the field of agriculture development.

From analyzing the content of agriculture-related articles in VnExpress in particular and online newspapers in Vietnam in general, some advantages and disadvantages of mass media in agriculture development in Vietnam can be summarized as follow:

Advantages. For the Government, the role of online media is expressed in three fundamental aspects:

Firstly, the media helps to propagate and disseminate Vietnam's agricultural achievements in order to change public awareness, attitudes, and behaviors. Through the online media, the Party and the State of Vietnam have affirmed the importance of Vietnam's agriculture development and continuously improving agriculture-related laws and policies.

Secondly, by collecting public opinion through online media, the State makes policy adjustments before issuing legal documents to create social consensus and innovate in agricultural activities management.

Thirdly, through the social monitoring and criticism role of the media, the Government listened to the opinions of scientists, journalists, and people's voices to make adjustments in the restructuring of the agricultural sector, enhance the production of high-value agricultural products, to build hi-tech agricultural models, organic agriculture and clean agriculture, towards sustainable development

For the citizens, online media is an important channel to update information on agricultural activities, an important economic component of Vietnam.

Besides, online media raise a forum for people to respond, speak up, and protect their legitimate rights and interests. Proposals to the State for sustainable agriculture development were made by the scientists and agricultural experts on the mass media. Farmers and businesses peoples share their views through journalists, express their aspirations in newspapers. 
Disadvantages. In addition to the above achievements, online media also has some limitations in agriculture development in Vietnam.

It is found that the online media have not extensively played roles in communicating agriculture development to the people and conveying people's opinions and aspirations on this issue to the Government and businessman. Some urgent issues in the field of agriculture development arise. They are the lives of farmers, who are performing the most crucial task of ensuring national food security, those who struggle to cultivate to feed the people, but unfortunately, they are always poor, have not been much covered in the online newspapers about their inadequacy. The online newspapers need to recognize that, in the country, where the economy is largely based on agriculture, however, many farmers are more deprived and are more likely to leave their fields to work as labor in industrial parks rather than working in their ancestral lands, this is really a worrying issue. The online newspapers need to turn these issues into "agendas" to attract the attention of policymakers and the whole society for the change. Otherwise, many people will move to social media to listen to the real problems of Vietnamese agriculture and raise their voices over there.

Besides, audiences, especially farmers, have not fully used online media to express their aspirations and speak out about agriculture development, and the problems they face in that field. In the agricultural forums created on the online media, farmers were very limited in expressing their views. Maybe they live in rural areas, with less limited internet connection than in urban areas, or another reason is the low self-esteem and shyness of farmers, and the online media have not given them the motivation to raise their voice too.

\section{Recommendations}

The Party and the State of Vietnam always determine the importance of agricultural and rural development. The Document of the XII Congress of the Party pointed out: "Building agriculture towards the direction of large commodity production, high technology application, product quality improvement, assurance of food hygiene and safety; improve added value, boost exports" (Communist Party of Vietnam, The Documents of the 12th National Congress, National Political Publishing House, Hanoi, 2016). That goal can only be successfully achieved by widely communicating to the masses, mobilizing, and organizing them to join. At the same time, improved policies and executive capacity of the social management system. The following issues need to be paid attention to enhance the role of the media in agriculture development in Vietnam

Firstly, on the side of the State management agencies, it is necessary to see the particularly important role of the media in enhancing the communication activities on agriculture development. Besides compiling, printing and distributing propaganda spreading documents, legal documents, question and answer documents on agriculture for officials and employees working in agriculture and farmers; organizing agricultural training conferences in provinces and cities; supporting agricultural bookshelves in communes, wards, towns, and so on. It is needed to see that the mass media like print newspapers, radio, television, especially online newspapers, social networks on the platform of the Internet is a handy communication channel to increase communication activities. As the Agenda-setting theory points out, the media has a significant influence on public awareness of important issues. If state management agencies consider agriculture development as relevant information, it should be promoted in the mass media.

Secondly, for the media side, it is important to realize that agriculture, farmers, and rural areas always play an essential role in Vietnam's socio-economic development strategy and need to be promoted communication about them. Because propagating information is the most basic and prerequisite function of online media. Online media exist to work first of all to meet the increasing information needs of people and society. On the other hand, the 
information on online media is also the material and driving force of socio-economic development. Information is a direct factor affecting public opinion.

It shows that online media have a significant advantage in disseminating common policies to all segments of the population. It is the most important factor to ensure the democratization of social processes and social relations on a large scale. The publicity factor of the online media limits the ability of the monopoly of information inherent in the direct communication mechanism to be limited to a few social classes. Through the mechanism of mass communication, the ability to transmit and receive information of the masses is expanded than the mechanism of direct communication that was popularized in traditional societies. Therefore, information on agriculture development needs to be strengthened in the online media, thereby directing and shaping the bona fide social opinion in this field.

At last, on the citizen side, it is necessary to be aware of the rights and responsibilities of each person in developing Vietnam's agriculture, recognizing that online media are extremely effective channels for updating information. Regarding agriculture, it is also a forum to speak up and protect the rights and legitimate interests of the people. In 217 articles surveyed in VnExpress and many articles in other online newspapers, not so many articles on agriculture have the participation of public comment. If surveying social networks, there will certainly be opinions and comments from people about this issue and we will discuss in another paper. In online newspapers, readers often have feedback on many other topics. However, it seems that the discussion about agriculture is still very modest. So each citizen himself needs to be more responsible for agriculture development in Vietnam.

\section{References}

1. W. Verbeke, European Review of Agricultural Economics 32(3), 347-368 (2005)

2. G.W. Norton, J. Alwang, Applied Economic Perspectives, and Policy 42(1), 8-20 (2020)

3. R.S. Llewellyn, B. Brown, Applied Economic Perspectives and Policy 42(1), 100-112 (2020)

4. W. Morris, P. James, Journal of Small Business and Enterprise Development 24(4), 1028-1045 (2017)

5. B.B. Balkrishna, A.A. Deshmukh, Global Journal of Management and Business 17, 1E (2017)

6. M. Irfan, S. Khan, G.A. Asif, International Journal of Agriculture and Biology (Pakistan) 8(3), 417-419 (2006)

7. B.K. Ravi, Academic media and agriculture - Part I: Natural and Applied Sciences 4(4), 293-310 (2013)

8. S.C. Babu, P.K. Joshi, V.R. Sulaiman, Academic Press Elsevier, 41-60 (2019)

9. S.P. Marsh, T.G. MacAulay, Australasian Agribusiness Review 10(19), 1-19 (2002)

10. S. Pandey, N.T. Khiem, H. Waibel, T.C. Thien, Household Food Security, and Commercialization of Agriculture in Uplands of Vietnam: A Micro-Economic Analysis (International Rice Research Institute, Philippines, 2006)

11. A. de Brauw, Journal of Development Studies 46(1), 114-139 (2010)

12. Q.N. Mai, The Journal of Sociology 3(83), 9-14 (2003)

13. L. Brandt, D. Benjamin, Agriculture and Income Distribution in Rural Vietnam under Economic Reforms: A Tale of Two Regions (University of Michigan, 2002) 
14. T.B.L. Hoang, H.P. Dinh, The Journal of Vietnamese Social Sciences 10(107), 15-23 (2016)

15. Oxford English Dictionary Online (Oxford University Press, 2008)

16. N. Luhmann, The Reality of the Mass Media (Stanford University Press, 2000)

17. Newspapers Recreate Their Medium (Wayback Machine eJournal, USA, 2006)

18. The Hao, Ha Chi, Journal of Information Security 12 (2019)

19. M.E. McCombs, D.L. Shaw, Public Opinion Quarterly 36(2), 176-187 (1972)

20. T.L. Nguyen, Journal of Electronic Journalist 6 (2016)

21. H.P. Nguyen, Some issues on socio-economic, cultural and development morphology (The Social Sciences Publishing House, Hanoi, 2000) 